\section{RMD Open}

Rheumatic \& Musculoskeletal Diseases

Workforce requirements in

\title{
rheumatology: a systematic literature review informing the development of a workforce prediction risk of bias tool and the EULAR points to consider
}

\author{
Julia Unger, ${ }^{1}$ Polina Putrik, ${ }^{2}$ Frank Buttgereit, ${ }^{3}$ Daniel Aletaha, ${ }^{4}$ Gerolamo Bianchi, ${ }^{5}$ \\ Johannes W J Bijlsma, ${ }^{6}$ Annelies Boonen, ${ }^{2}$ Nada Cikes, ${ }^{7}$ João Madruga Dias, ${ }^{8}$ \\ Louise Falzon, ${ }^{9}$ Axel Finckh, ${ }^{10}$ Laure Gossec, ${ }^{11}$ Tore K Kvien, ${ }^{12}$ Eric L Matteson, ${ }^{13}$ \\ Francisca Sivera, ${ }^{14}$ Tanja A Stamm, ${ }^{15}$ Zoltan Szekanecz, ${ }^{16}$ Dieter Wiek, ${ }^{17}$ \\ Angela Zink, ${ }^{3,18}$ Christian Dejaco, ${ }^{19,20}$ Sofia Ramiro ${ }^{21}$
}

To cite: Unger J, Putrik P, Buttgereit $F$, et al. Workforce requirements in rheumatology: a systematic literature review informing the development of a workforce prediction risk of bias tool and the EULAR points to consider. RMD Open 2018;4:e000756. doi:10.1136/ rmdopen-2018-000756

- Prepublication history and additional material for this paper are available online. To view these files, please visit the journal online (http://dx.doi. org/10.1136/rmdopen-2018000756).

JU and PP contributed equally.

Received 1 July 2018

Revised 8 September 2018 Accepted 15 October 2018

Check for updates

(C) Author(s) (or their employer(s)) 2018. Re-use permitted under CC BY-NC. No commercial re-use. See rights and permissions. Published by BMJ.

For numbered affiliations see end of article.

Correspondence to Dr Christian Dejaco; christian.dejaco@gmx.net

\section{ABSTRACT}

Objective To summarise the available information on physician workforce modelling, to develop a rheumatology workforce prediction risk of bias tool and to apply it to existing studies in rheumatology.

Methods A systematic literature review (SLR) was performed in key electronic databases (1946-2017) comprising an update of an SLR in rheumatology and a hierarchical SLR in other medical fields. Data on the type of workforce prediction models and the factors considered in the models were extracted. Key general as well as specific need/demand and supply factors for workforce calculation in rheumatology were identified. The workforce prediction risk of bias tool was developed and applied to existing workforce studies in rheumatology.

Results In total, 14 studies in rheumatology and 10 studies in other medical fields were included. Studies used a variety of prediction models based on a heterogeneous set of need/demand and/or supply factors. Only two studies attempted empirical validation of the prediction quality of the model. Based on evidence and consensus, the newly developed risk of bias tool includes 21 factors (general, need/demand and supply). The majority of studies revealed high or moderate risk of bias for most of the factors.

Conclusions The existing evidence on workforce prediction in rheumatology is scarce, heterogeneous and at moderate or high risk of bias. The new risk of bias tool should enable future evaluation of workforce prediction studies. This review informs the European League Against Rheumatism points to consider for the conduction of workforce requirement studies in rheumatology.

\section{INTRODUCTION}

Rheumatic and musculoskeletal diseases (RMDs) are highly prevalent and, according to the burden of disease report, present a

\section{Key messages}

What is already known about this subject?

- The projections from existing workforce studies in rheumatology vary by a factor of five, largely due to methodological heterogeneity.

What does this study add?

- This study provides a synthesis of information of the workforce prediction literature in rheumatology and other medical fields about general aspects, supply, need and demand factors considered in workforce models.

- We hereby use a self-developed workforce prediction risk of bias tool to guide and assess the quality of workforce studies in rheumatology.

How might this impact clinical practice?

- The developed tool is meant to improve the methodological quality of future workforce studies and ultimately to lead to better workforce planning in rheumatology.

- This review informs the European League Against Rheumatism points to consider for the conduction of workforce requirement studies in rheumatology.

major cause of disability-adjusted life years worldwide. ${ }^{1}$ Due to population growth, ageing and improved diagnosis, the prevalence of RMDs in developed countries increased by $60 \%$ from 1990 to $2010 .^{2}$ While expert consensus exists with respect to how best manage RMDs in order to prevent adverse long-term consequences, ${ }^{3-5}$ inadequate manpower documented in many countries hinders implementation of these recommendations. ${ }^{67}$ Workforce planning in 
healthcare is further challenging due to time and costs involved in training of new physicians. Methodologically sound workforce planning should guide policy decisions on the number of students entering into education and medical training programmes. ${ }^{8}$

A recent systematic literature review (SLR) on workforce projection models in rheumatology from Western countries identified a large heterogeneity in methods for projecting the rheumatology workforce needs. ${ }^{9}$ Notably, published studies covered only a handful of Western countries, and the resulting projections from available studies varied by a factor of five ${ }^{9}$ and are thus not a reliable basis for political decisions. Therefore, the development and implementation of a sound approach to health workforce planning is needed to ensure access of the population to best practice disease management.

The need for an agreed-on methodology for workforce predictions is discussed not only in the field of rheumatology. A number of workforce prediction studies have also been conducted in other medical fields. ${ }^{10-12}$ It is likely that major principles of workforce modelling are common to other specialties in medicine. To date, however, insufficient attention has been given to synthesise the existing evidence on methodologies used for workforce predictions. To our knowledge, there has been no attempt so far to agree on a standard methodology for the conduction of workforce studies, nor has there been any attempt to appraise such studies for methodological quality and risk of bias.

The overarching aim of this SLR was to inform the European League Against Rheumatism (EULAR) task force working on 'points to consider' for the conduction of workforce requirement studies in rheumatology. ${ }^{13}$ The specific objectives of the present work were (1) to perform an update of the published SLR on workforce prediction in rheumatology, ${ }^{9}$ (2) to conduct a hierarchical SLR (overview of reviews) of workforce prediction models in other medical fields, and (3) using available data to develop a workforce prediction risk of bias tool and to apply it to existing workforce studies in rheumatology.

\section{METHODS}

\section{Design of the systematic literature search}

We conducted two SLRs, including an update of an SLR of workforce requirement studies in rheumatology ${ }^{9}$ and a hierarchical SLR (which is an overview of systematic reviews) of workforce prediction studies in other medical fields (including all medical specialties, but also related areas like nursing, physiotherapy and pharmacy) in Western countries.

\section{Search strategy and eligibility criteria}

The EULAR task force to develop 'points to consider' for the conduction of workforce requirement studies in rheumatology outlined the scope of the literature search according to the PICO (Population, Intervention, Comparator, Outcomes) format. The population was defined as (1) adult rheumatologists (for the update of the recent SLR in rheumatology) and (2) other medical fields, namely medical specialists and other health professionals (for the hierarchical search). The scope of the update did not include paediatric rheumatologists. The intervention was defined as (1) the type of workforce model, (2) the factors used to build up the model or (3) the empirical data used for the calculation of workforce requirements. The comparator could not be defined for this review question. The outcome was defined as the number of rheumatologists/other specialists needed to serve the (general) population. Studies with any time frame for predictions, including those making calculations for baseline only (ie, calculations referring to the year when prediction has been made), were included.

For the update search in rheumatology, we used the same search strategy and eligibility criteria as in Dejaco et al. ${ }^{9}$ MEDLINE, Embase, PubMed, CINAHL and the Cochrane Library were searched (Search Strategy in the Online Supplementary Text S1) between 1 November 2015 (date of the original search) and 6 October 2017. The search strategy for the hierarchical SLR was designed by an experienced librarian (LF). First, using known studies on workforce prediction in other fields, a number of searches were run in PubMed applying special features to find similar articles and/or SLRs where these studies were included, followed by a cited reference search on Web of Science. Further, using a set of search terms (online supplementary text S2), we conducted a search in MEDLINE and Cochrane library (1946 to 29 September 2017), PubMed Clinical Queries and PubMed Health (both limited to SLRs and to 2017).

In order to get a full scope of practices in workforce prediction in rheumatology and other medical fields, we also searched for grey literature including screening homepages of 37 societies of rheumatology and other medical associations between May and September 2017 (online supplementary table S1). The following search terms were used: 'workforce models', 'workforce', 'forecasting', 'workforce forecasting', 'calculating workforce', 'workforce planning', 'workforce supply' and 'workforce demand'. Additionally, we emailed national societies of rheumatology to enquire about how the rheumatology workforce calculation was done at a national level (online supplementary table S2). Furthermore, authors of the studies retrieved by the original SLR were inquired whether any post-evaluations of the published model quality and accuracy had been performed.

\section{Study selection and data extraction}

For both searches, references and abstracts were imported into the reference management software Endnote V.X7.0.2. Duplicates were removed. Two researchers (JU and PP) independently screened all abstracts and titles. Next, full texts were reviewed to determine eligibility. Disagreements were resolved by discussion, and if necessary, a third author (SR) was involved to make a final decision. 
For both searches, study details and results of eligible studies were retrieved using a standardised data extraction sheet. For the SLR in rheumatology, we extracted data on the same parameters as in the original SLR, ${ }^{9}$ mainly on factors related to demand/need and supply of rheumatologists, as well as country, year, total number of rheumatologists required to serve the population and type of model. Additionally, information about regional heterogeneity, uncertainty analyses, application of any weighting of included factors, stakeholder involvement, role of other health professionals as well as employment trends were extracted from the 11 studies in the original $\mathrm{SLR}^{9}$ and the newly identified papers.

For the SLR in other medical fields, the following data were extracted: (1) study characteristics, including information about authors, year, medical field, design, objective, numbers of studies reviewed and sponsor/ grants; and (2) content of the study, including information about type of workforce models, country, number of studies using the specific model, advantages and disadvantages of models, factors related to supply, need and demand, regional heterogeneity, uncertainty analyses, stakeholder involvement, prediction quality and others.

The quality of the SLRs was not assessed as we were mostly interested in reviewing which models and underlying factors have been used in other fields and not in the prediction results of these studies.

\section{Development of a rheumatology workforce prediction risk of bias tool}

Based on the results of both literature reviews, key factors for workforce prediction models were identified. These included general factors (eg, type of the model, stakeholder involvement) as well as factors specifically related to the prediction of the workforce need/demand (eg, percentage of referrals to rheumatologist, epidemiology of diseases) and supply (eg, time spent on rheumatological care, entry and exit from the profession). Three risk of bias levels (low, moderate or high) were distinguished for each factor, with a clear description of which evidence would correspond to each of the levels. High risk of bias indicates that the factor was not or was only insufficiently considered in the workforce prediction model (without reasonable justification); low risk of bias corresponds to a well-considered factor in sufficient level of detail and based on reliable evidence. A moderate risk of bias reflects that the factor was partially described but without full level of detail. The decisions were driven by available evidence in rheumatology and other medical fields as well as task force expertise, with a few informal rounds to define the number of factors, shape and optimise the wording. We developed this workforce prediction risk of bias tool in order to use it for evaluating the risk of bias of the existing workforce modelling studies in rheumatology.

\section{RESULTS}

For the SLR in rheumatology, the literature search yielded 3221 hits. Screening of homepages (online supplementary table S1), contacting national rheumatology societies (37/49 answered; online supplementary table S2) and hand searches yielded seven additional records. After removing duplicates, a total of 2453 articles remained. After a formal assessment, three studies were included and added to the existing 11 , so in total there were 14 studies in rheumatology chosen for analysis (flowchart in online supplementary figure S1). The SLR in other medical fields yielded 4649 articles, of which 10 articles met the inclusion criteria (flowchart in online supplementary figure S2).

\section{General characteristics of workforce prediction studies in rheumatology}

General characteristics of the 14 workforce prediction studies in rheumatology are presented in table 1 . Studies were performed for the USA $(n=4),{ }^{14-17}$ Canada (n=3), ${ }^{18-20}$ Germany (n=3), ${ }^{721}{ }^{22}$ UK (n=2), ${ }^{23} 24$ Spain $(\mathrm{n}=1)^{25}$ and one study covered USA and Canada $(\mathrm{n}=1){ }^{26}$ Most studies $(\mathrm{n}=8)^{71415} 1719212225$ used some form of an integrated model, which included demand, need and supply factors, and four studies considered the existing imbalance between demand and supply at baseline. ${ }^{14171924}$ Half of the studies $(n=9)$ provided predictions for the future (as opposed to limiting predictions to study time), ${ }^{714-17} 19202526$ with a time horizon varying between 10 and 20 years. An assessment of the model performance was attempted by a total of four studies, ${ }^{715-17}$ with two studies having done an update of an earlier prediction. ${ }^{717}$ Both studies reported inaccuracies in the previous prediction, due to underestimating the retirement tendencies and employment patterns (part-time work) of female rheumatologists ${ }^{17}$ or changes in the life expectancy and demographic characteristics of the population. ${ }^{7}$ While more than half of the studies did not perform uncertainty analyses, a few reported some form of uncertainty analyses by considering variation in one or several parameters (eg, population growth, insurance coverage, income growth)..$^{14} 151725$ Three studies took regional heterogeneity into account. ${ }^{71617}$ Involving stakeholders from multiple disciplines was not common practice as it was only done in a few studies performed by large study groups. ${ }^{71517}$ Detailed information about the three newly included studies is depicted in online supplementary table S3-S5.

\section{Factors related to need/demand for rheumatology care}

Table 2 provides an overview of factors that influence the need/demand for rheumatology care. Large heterogeneity was observed with regard to the scope of the diseases covered by rheumatologists, even within the same countries. ${ }^{74-17} 19$ 21-25 Most of these studies have also estimated the percentage of patients referred to rheumatologists. ${ }^{714} 151719212324$ Rheumatologist workload in terms of numbers of visits per year was included 


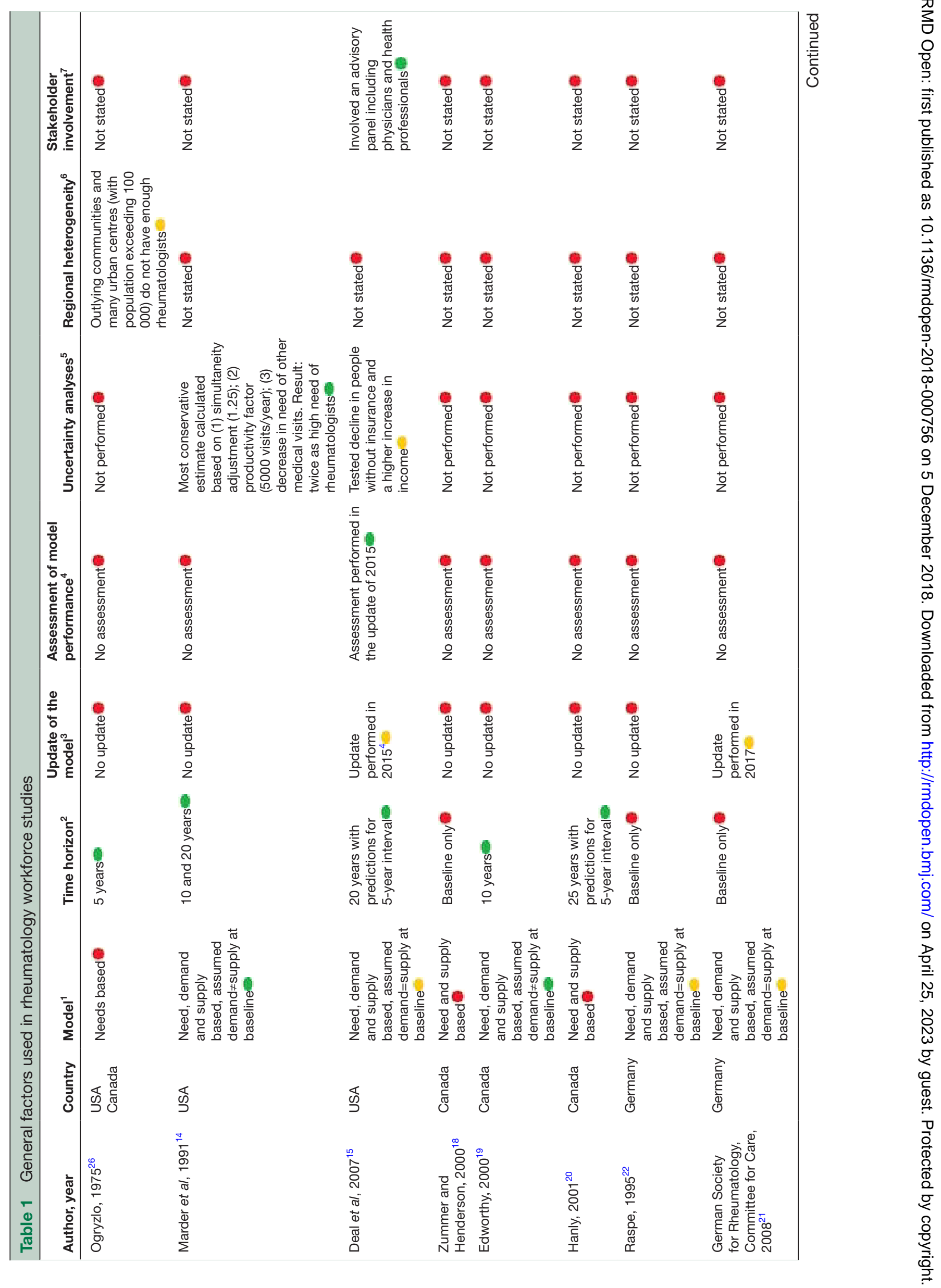




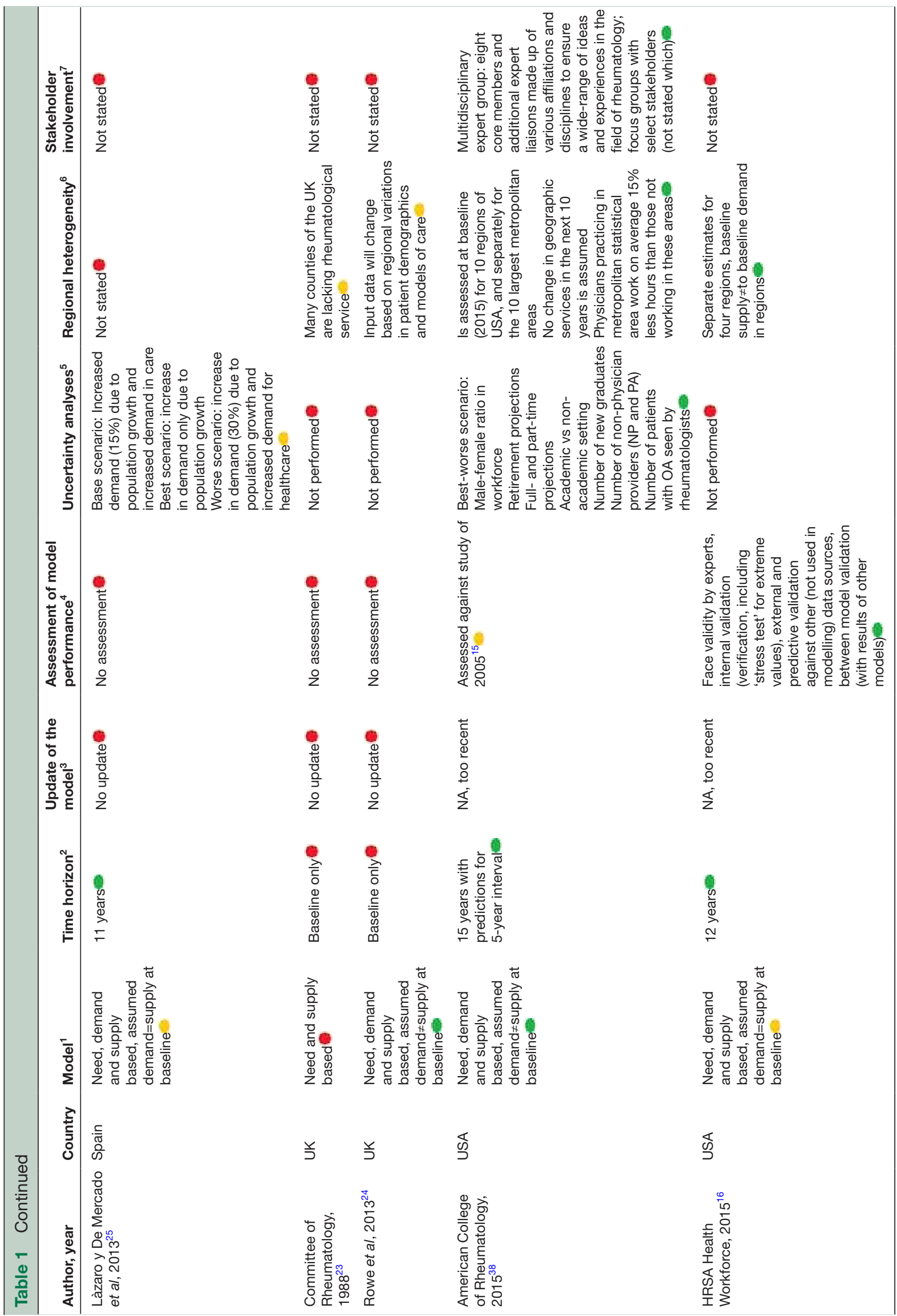




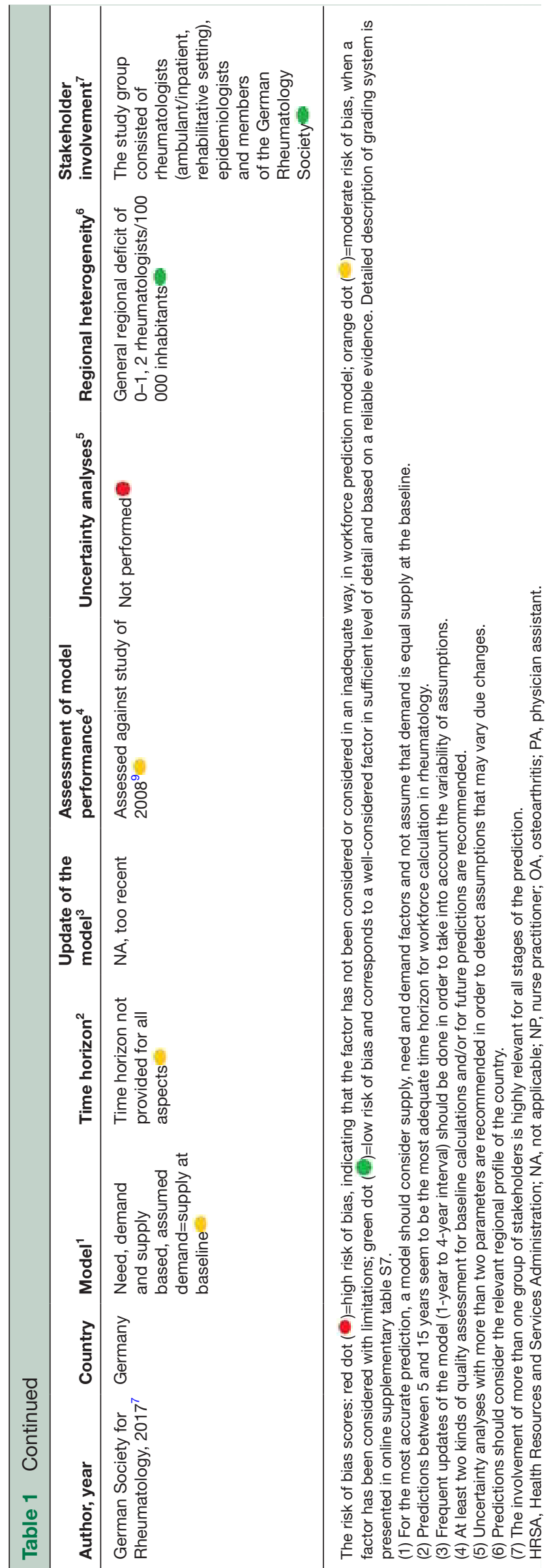

in six studies. ${ }^{7} 1419212224$ Projections of population ageing were considered by most of the studies ${ }^{714-18} 2025$; however, epidemiological developments ${ }^{17}$ or economic factors ${ }^{7} 15-17$ such as insurance or household income were rarely included in the predictions. The potential of medical development to modify the demand and need for care has been acknowledged in a number of studies; however, it not actually modelled into the predictions because of difficulty in making robust assumptions.

\section{Factors related to supply of rheumatologists}

Table 3 shows supply-based factors considered by the studies. Most of the studies $(\mathrm{n}=11)^{714161719-25}$ described the clinical setting, with few studies making their predictions for multiple settings, for example, private and public. Time spent on rheumatological care (as opposed to teaching or administrative tasks) was considered in 10 out of 14 models $^{7} 141517$ 19-22 24 25; however, it should be noted that the data used for calculations were frequently based on authors' assumptions. Effects of task shifting between professionals (eg, increasing role of nurse professionals in care) was another difficult to estimate factor, with only few studies making an attempt to put this into numbers. ${ }^{1415172324}$ Predictions of the entry to (eg, training) and exit (eg, emigration, illness) from the profession were considered. ${ }^{14-19} 2526$ Workforce demographic trends comprised an important part of the future workforce prediction. Estimation of the number of physicians projected to retire and/or gender structure of future workforce was incorporated in 8 of 14 models. ${ }^{74-182025}$ An important trend of more women entering the profession has been observed in a few studies, ${ }^{15-17} 2025$ and, given that women are more likely to work part-time, this had important implications for the number of physicians to be trained. Studies typically presented the results of prediction in headcounts (ie, number of rheumatologists). Four studies (three of which were found in update search) also presented fulltime equivalents (FTEs). ${ }^{7161720}$

\section{Manpower requirements in other medical fields}

The 10 SLRs from the second search (overview of systematic reviews) covered a heterogeneous scope of areas, including nurses $(\mathrm{n}=2),{ }^{27}{ }^{28}$ pharmacists $(\mathrm{n}=1),{ }^{29}$ paediatric specialties $(\mathrm{n}=1),{ }^{30}$ public health $(\mathrm{n}=1)^{31}$ and studies that were not limited to any specialty $(n=3)^{32-34}$ or considered a mix of specialties $(\mathrm{n}=2)^{3536}$ (online supplementary table S6).

Of the 10 , only two reviews ${ }^{35} 36$ actually provided a summary of the workforce projections, and none has provided an assessment of the model performance. The remaining reviews synthesised models from a methodological and theoretical point of view, describing which models were used and which need, demand and supply factors should be considered.

While most of the SLRs acknowledged the relevance of regional heterogeneity, only one considered it by making different predictions according to the region or 


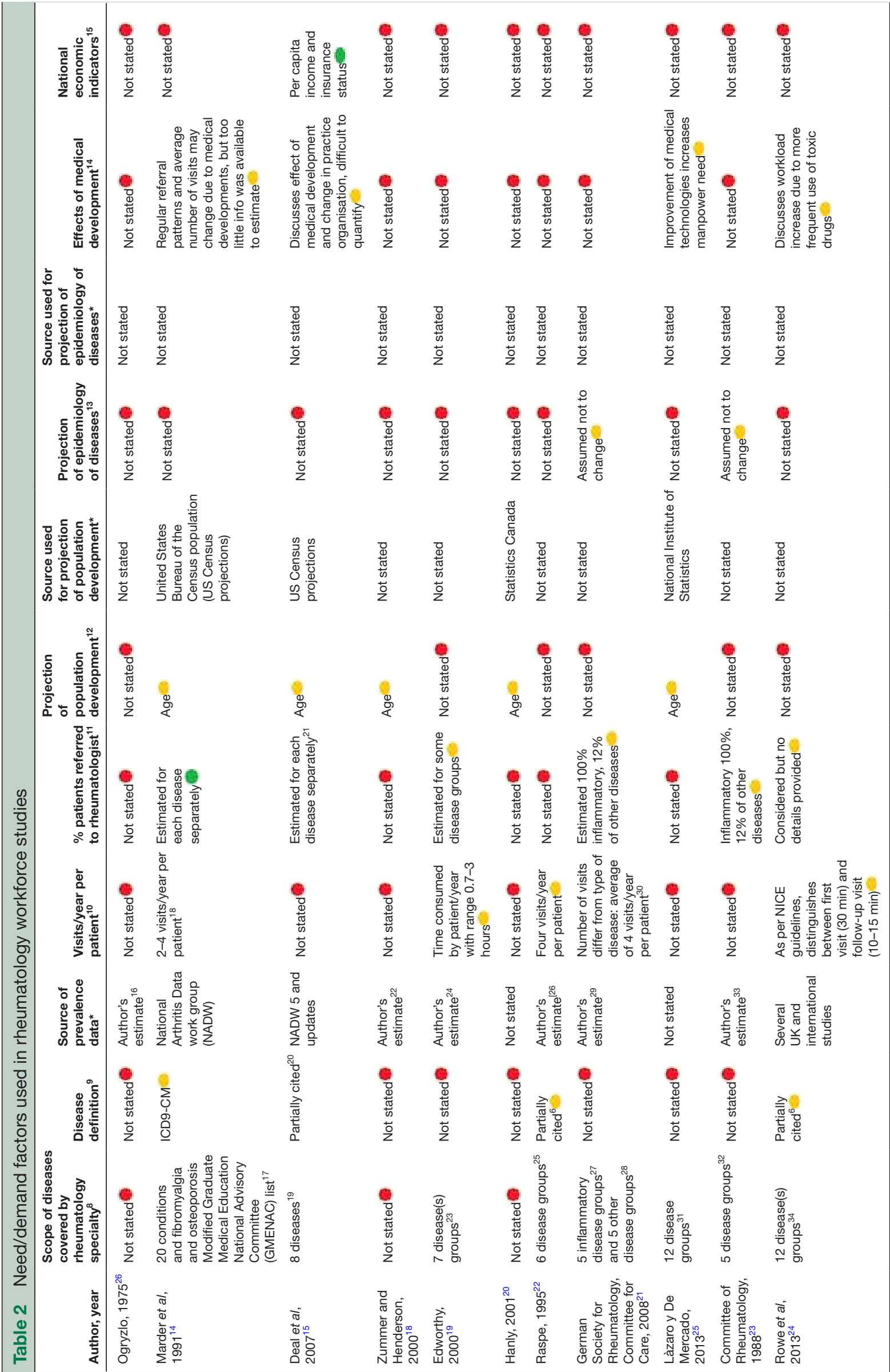




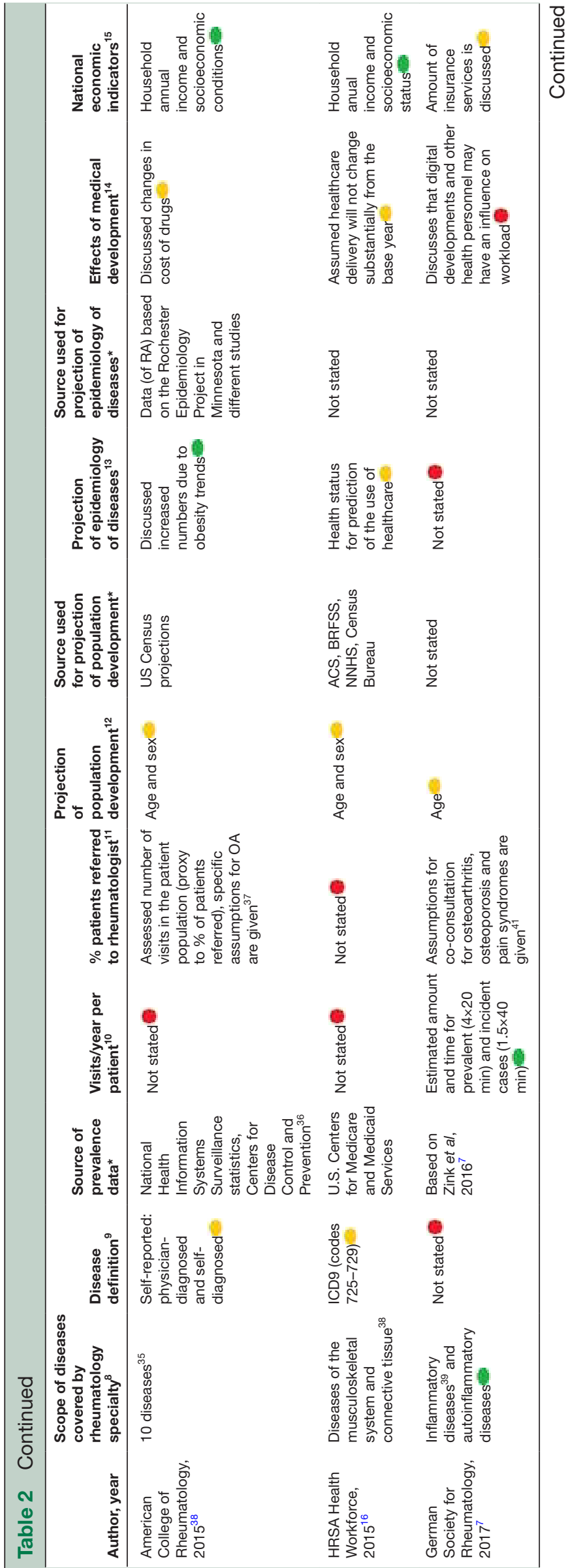

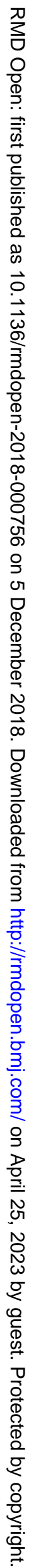




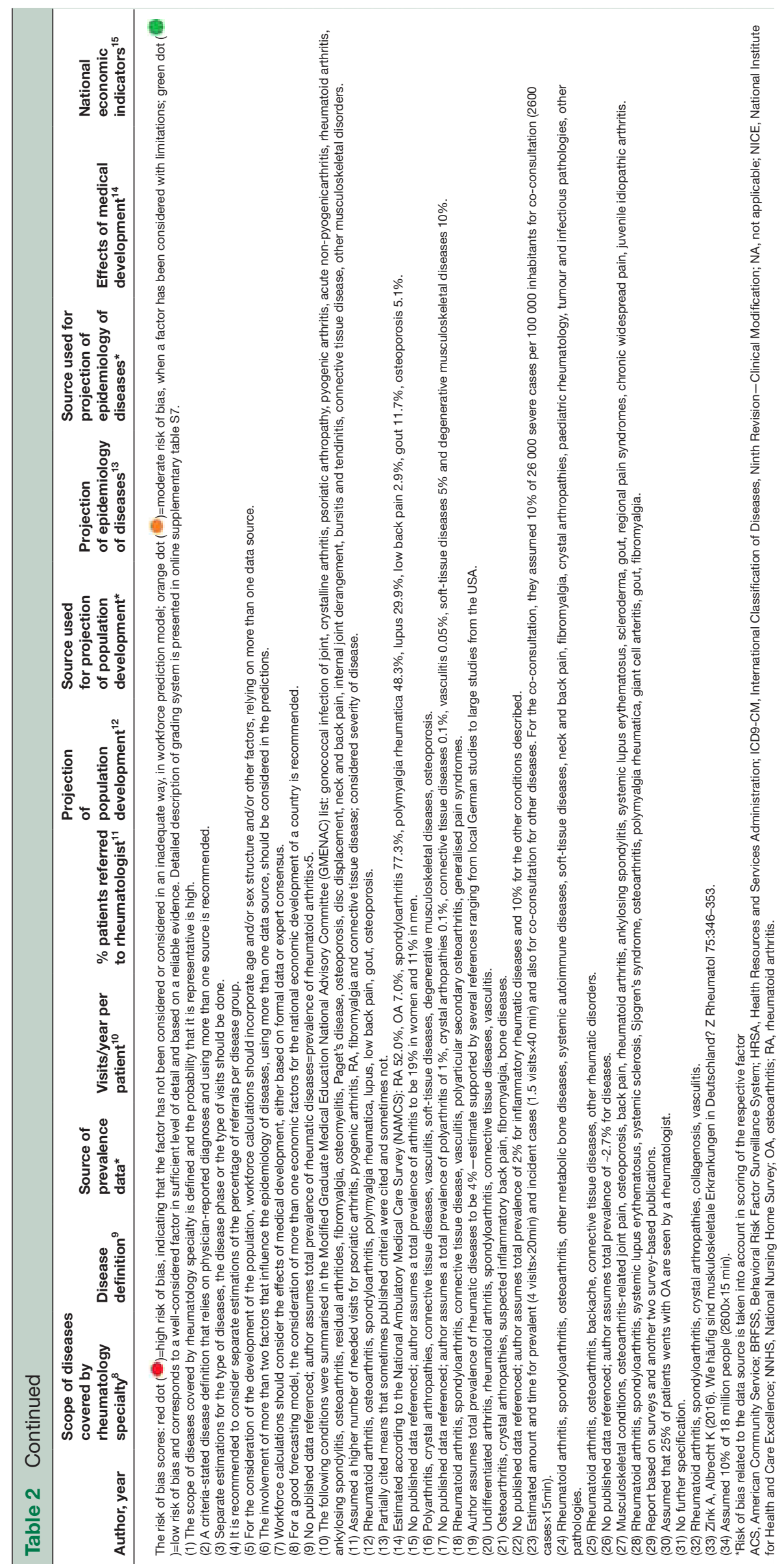




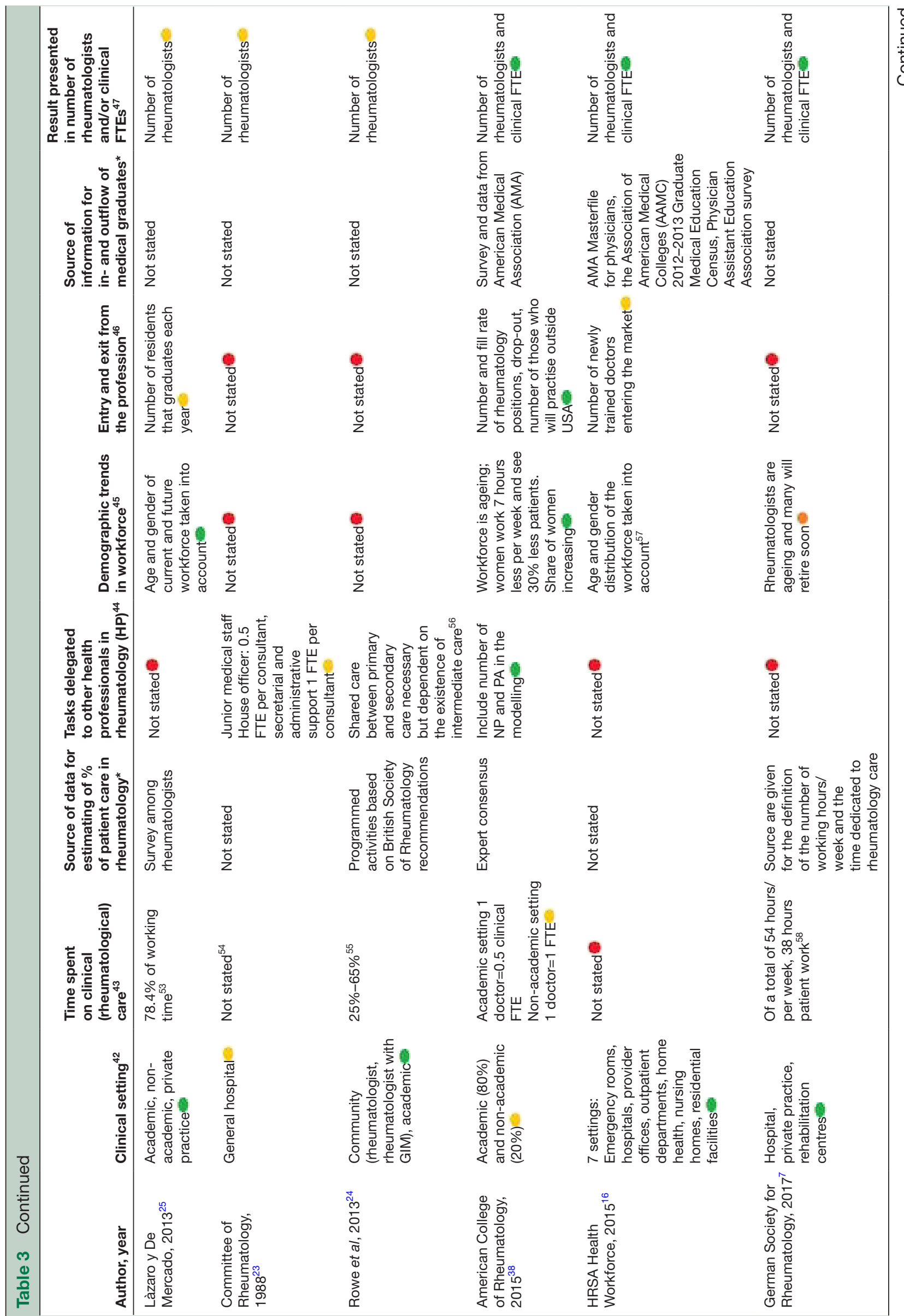




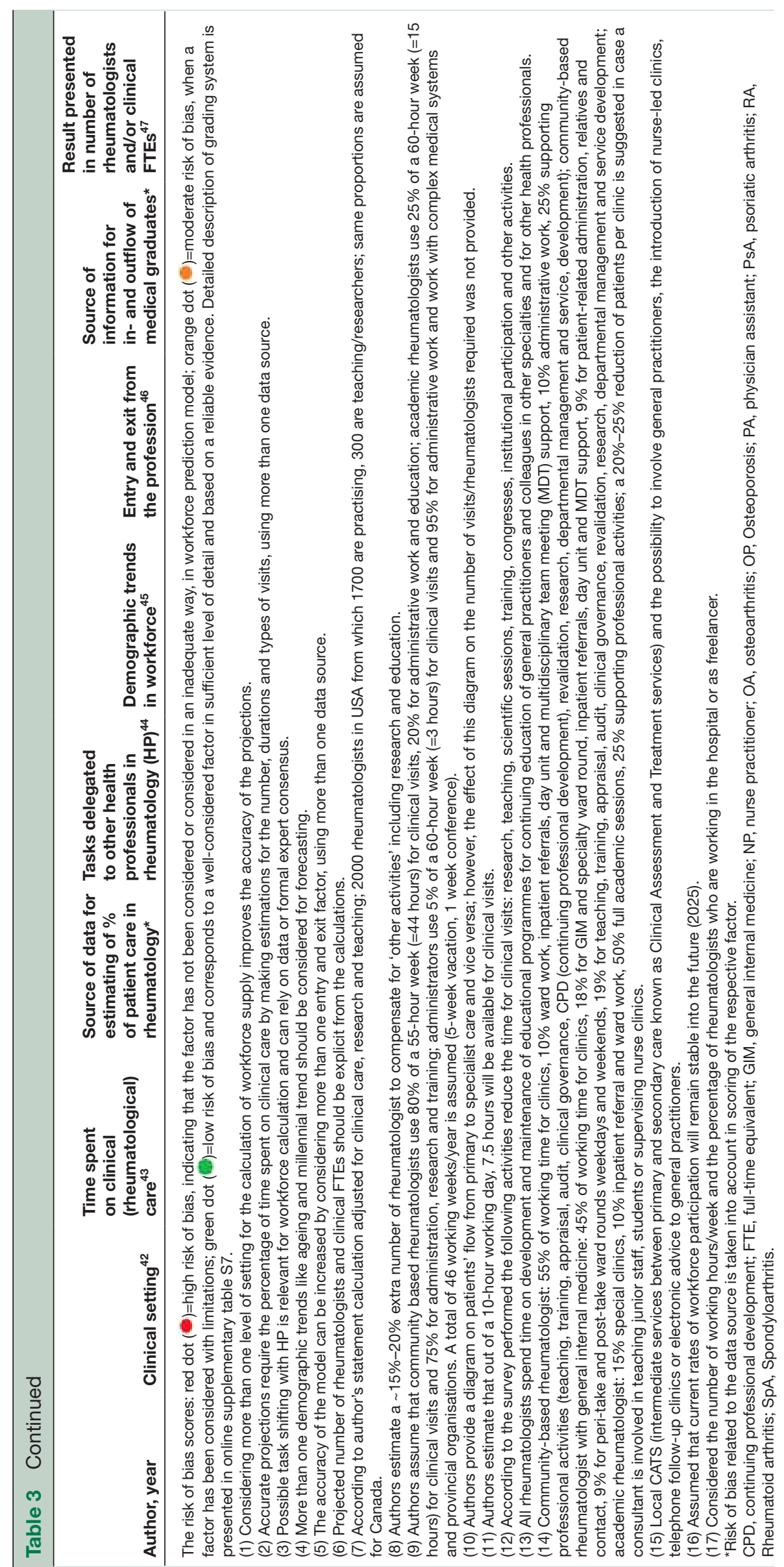


Table 4 Need/demand and supply factors identified from systematic literature reviews of workforce studies in other medical fields than rheumatology

Factors of need/demand and supply that were discussed in relation to workforce modelling process factor

Demand/need factors

Use patterns, market factors (eg, access to services and preferences of health consumers), insurance 6 studies ${ }^{27} 2931323435$ coverage

Morbidity, mortality, incidence and severity, degree of need (dependency-acuity method)

6 studies $^{27} 2832-35$

Population growth, ageing

7 studies $^{27} 30-35$

Desirable service volume (estimated demand for care), in relation to population health referral volume

Changes in guidelines that can help to anticipate increase or decrease in need/demand

2 studies $^{27} 30$

Income and education level, deprivation

1 study $^{27}$

Geographical distribution, travel distances

2 studies $^{28} 34$

Adjustments for market inefficiencies ${ }^{1}$

2 studies $^{28} 30$

Technology development, increased complexity of care

1 study $^{32}$

Supply factors

Age structure, mortality, retirement, millennial and feminisation trends, full-time and part-time

4 studies $^{29} 323435$

unemployment, manpower work pattern

Substitution rates, entry into practice and attrition, foreign medical graduates

Clinical FTE or \% of non-clinical activities (research, teaching, travelling time, time out, time invested in $\quad 6$ studies ${ }^{28-30} 323435$ education)

Mobility patterns and practice style, migration

Increasing no of support staff, task shifting, skill mix, expansion in roles

General labour market regulations (eg, Working Time Directive), economic and political factors, unemployment

Productivity rates, caseload, referrals

9 studies $^{27-35}$

Practice organisation, staffing norms, skill mix

Payment methods, incentives

Job satisfaction factors

Spouse's employment status

3 studies $^{27} 2935$

3 studies $^{27} 2935$

6 studies $^{27}$ 30-34

4 studies $^{27} 283031$

2 studies $^{27} 35$

2 studies $^{27} 35$

2 studies $^{29} 31$

1 study $^{31}$

(1) Authors of the included studies have adjusted for known US health market inefficiencies, eg, that FFS (fee-for-service) practices require $56 \%$ more physicians compared with $\mathrm{HMO}$ (health maintenance organisations).

metropolitan area. ${ }^{3036}$ Three reviews reported uncertainty analyses by summarising different scenarios or results of simulation models. ${ }^{27} 3536$ The quality of prediction was discussed by more than half of the reviews $(n=6),{ }^{27} 2832-35$ without doing a formal quality appraisal, stating that quality improves when more parameters are considered in the model. On the other hand, poor quality of data has been acknowledged to have a profound impact on prediction results. Only two SLRs ${ }^{27}{ }^{35}$ recognised the importance of involving stakeholders as they form the background for decisions.

\section{Factors related to need/demand and supply in other medical fields}

Table 4 shows need/demand and supply-based factors considered in workforce prediction studies in other medical fields. Care use patterns and market factors (eg, access to services, preferences of health consumers, insurance coverage) were described but not always included in the workforce calculations. ${ }^{27} 2931323435$ Population growth and ageing, morbidity and mortality statistics was another group of commonly mentioned factors. ${ }^{27}{ }^{30-35}$ Factors like income and educational level $(n=2),{ }^{28} 34$ geographical distributions $(n=2)^{28} 30$ or service and referral volume $(\mathrm{n}=1)^{30}$ were less frequently discussed, and real examples of how these could be modelled in the workforce prediction were absent.

Workforce supply-related variables like workforce age, mortality, retirement, millennial (persons who entered workforce in the new millennia) and gender trends, full-time and part-time employment were considered (at least in part) by most of the reviews $(n=9) \cdot{ }^{27-35} \mathrm{Six}$ reviews $^{27}$ 29-33 also took substitution rates (eg, replacement of retiring physicians) and entry into practice into account. Factors related to time spent on clinical work or the percentage of non-clinical activities, time out (eg, career breaks) or time invested in education were covered by 6 of 10ten SLRs. ${ }^{29} 3032343537$ Fewer reviews considered mobility patterns and practice styles as well as migration $(n=3)^{27} 2935$ and task shifting to other health professionals $(n=3)^{272935}$ in their models. 
Most of the types of models and factors used were in line with the workforce prediction literature in rheumatology.

\section{Development of the workforce prediction risk of bias tool}

Based on the results of the literature review, 21 key factors for a workforce prediction model (see online supplementary figure S3) were identified. These factors were divided into three groups, namely, general factors, need/demand factors and supply-based factors. ${ }^{13}$ A short overview of the factors and the proposed grading system is depicted in table 5. A full description of the grading tool with the underlying rationale is given in online supplementary figure S7. Figure 1 summarises the envisaged structure of the potential comprehensive workforce prediction model that includes the factors outlined in the risk of bias tool.

\section{Application of the workforce prediction risk of bias tool}

We applied our workforce prediction risk of bias tool to 14 workforce studies in rheumatology. An overview of this assessment is provided in tables 1 and 2 and in online supplementary table S8-S10. No single study scored with a low risk of bias on all 21 factors, rather the majority of studies had high or moderate bias in several items. Quality of data sources, incorporated in some of the gradings, was one of the most important reasons for increasing the risk of bias. For example, if a workforce prediction study included task-shifting between professionals but calculations were based only on author's assumptions, it was graded as moderate, as opposed to when authors have obtained empirical data or a more formal expert consensus. In assessment of performance of general factors, several studies performed well in the choice of the model, ${ }^{14} 171924$ time horizon ${ }^{14-17} 192025$ and stakeholder involvement. ${ }^{71517}$ Highest risk of bias was found concerning the regular update of models and the assessment of model accuracy, both of which have rarely been done. Most studies failed to adequately consider regional heterogeneity and uncertainty analyses. Among demand/ need factors, reporting the scope of the diseases covered by rheumatologists was the only item in which most of the studies performed well. No single study achieved the lowest risk of bias score on disease definition, population projections and effects of medical developments. Among supply factors, the definition of clinical setting and demographic trends in workforce were adequately addressed in most studies, whereas task shifting, time dedicated to clinical care, or measuring the entry to and exit from the profession were frequently of low quality.

\section{DISCUSSION}

This study had three closely linked objectives, namely summarising the review of workforce prediction studies in rheumatology and other medical fields, as well as the development of a tool for the assessment of risk of bias of workforce studies and its subsequent application in rheumatology studies.
The review of workforce studies in rheumatology was an update of an earlier SLR. ${ }^{9}$ We have identified three new studies, two of them ${ }^{717}$ representing an update of the previously conducted workforce predictions in the USA and Germany. The updates of workforce calculations provide an important source of information for the assessment and validation of the models. Major conclusions of these updates referred to underestimations in the supply side of the models due to retirement patterns or gender trends (more women) in the rheumatology workforce resulting in a greater need for rheumatologists than previously predicted in order to cover the existing and expected future demand for care. ${ }^{17} 38$ Other sources of inaccuracy were forecasts around life expectancy and demographic developments, ${ }^{7}$ also resulting in a higher predicted need for care.

While methods and models used in the newly included studies were as heterogeneous as in older studies, in the most recent literature there was a tendency towards the use of integrated models with a wide range of relevant supply, need and demand factors. Two of the three new studies involved a multidisciplinary group and multiple stakeholders, ${ }^{7}{ }^{17}$ which seems appropriate given the complexity of the topic and the different users of the results. Another trend more commonly seen in recent studies was the expression of results in headcounts and FTEs acknowledging the increment in part-time work. Increasing efforts in workforce predictions from different countries and a growing body of evidence underline the need and timeliness of synthesising the literature into a more solid methodological basis for future studies in the area.

The overview of SLRs in other medical fields has led to several important insights. First, the need for accurate workforce prediction has also been voiced across different medical specialities. Second, no standardised approaches for workforce prediction exist in other medical fields, leading to a similar heterogeneity of methods and predictions as in rheumatology. Third, studies in other fields have taken into consideration workforce supply, demand and need factors similar to studies in rheumatology. Finally, workforce prediction in other fields faces challenges similar to those in rheumatology. These include accuracy and validation of the models, data quality, uncertainty around assumptions and to some extent stakeholder involvement and consideration of regional imbalances in larger countries. It is important to note that none of the systematic reviews in other medical fields reported an empirical evaluation of the workforce prediction model; hence, it remains unknown whether one can rely on the theoretical and conceptual assumptions provided and to what extent the suggested parameters improve model performance.

We have identified 21 key factors relevant for rheumatology workforce prediction, categorised into general factors and workforce need/demand and supply factors. Making use of these key factors, we developed a tool that can be applied for the assessment of the risk of bias of 


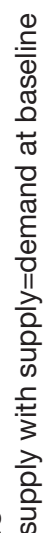

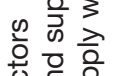

范

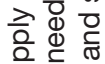

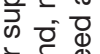

ᄒ

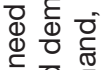

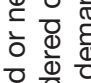

등 흥 응

离

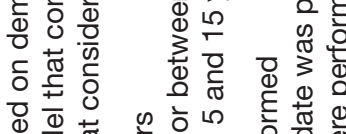

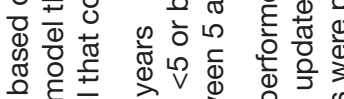

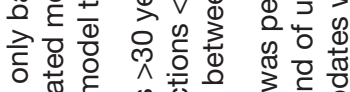

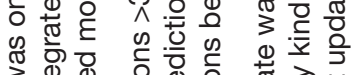

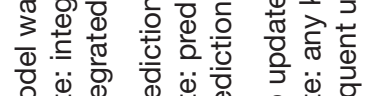

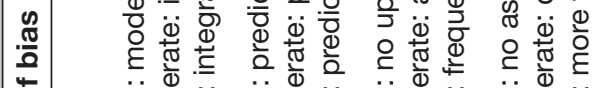

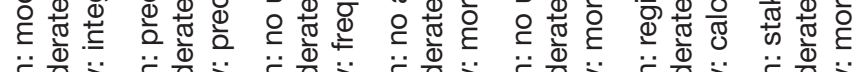

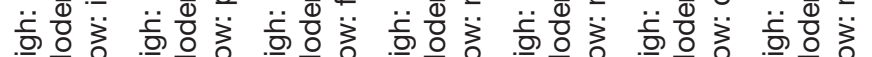

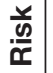

$\frac{*}{0}$

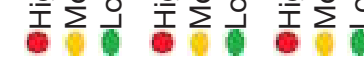

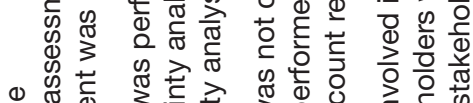

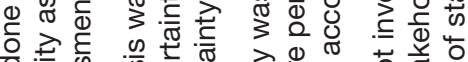

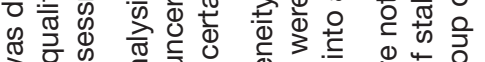

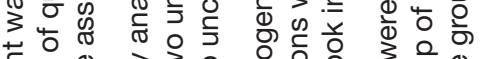

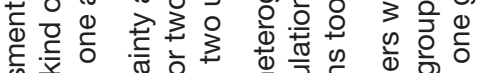

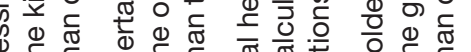

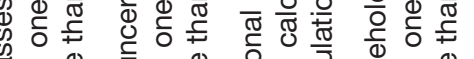

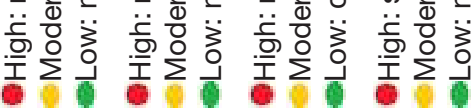

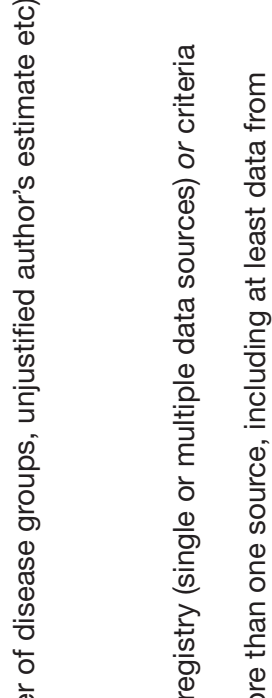

ब

है.

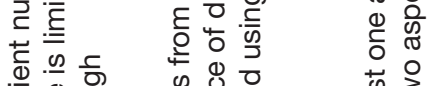

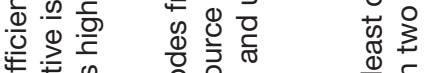

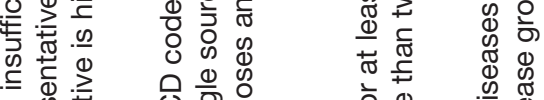

Di

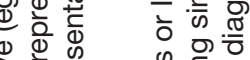

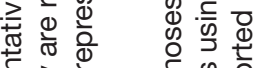

ब

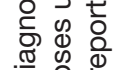

年

$\stackrel{d}{F}$

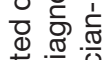

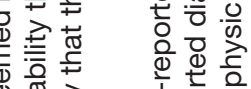

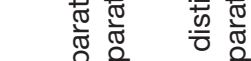

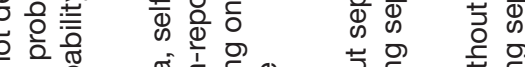

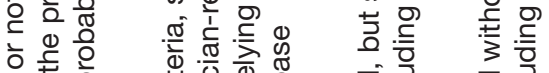

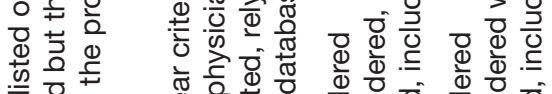

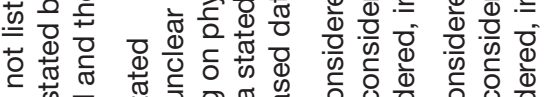

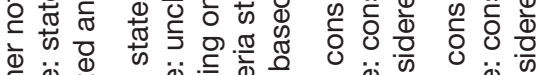

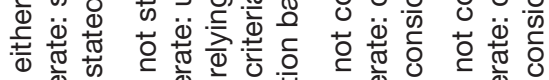

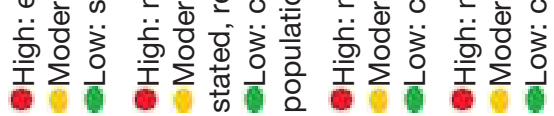




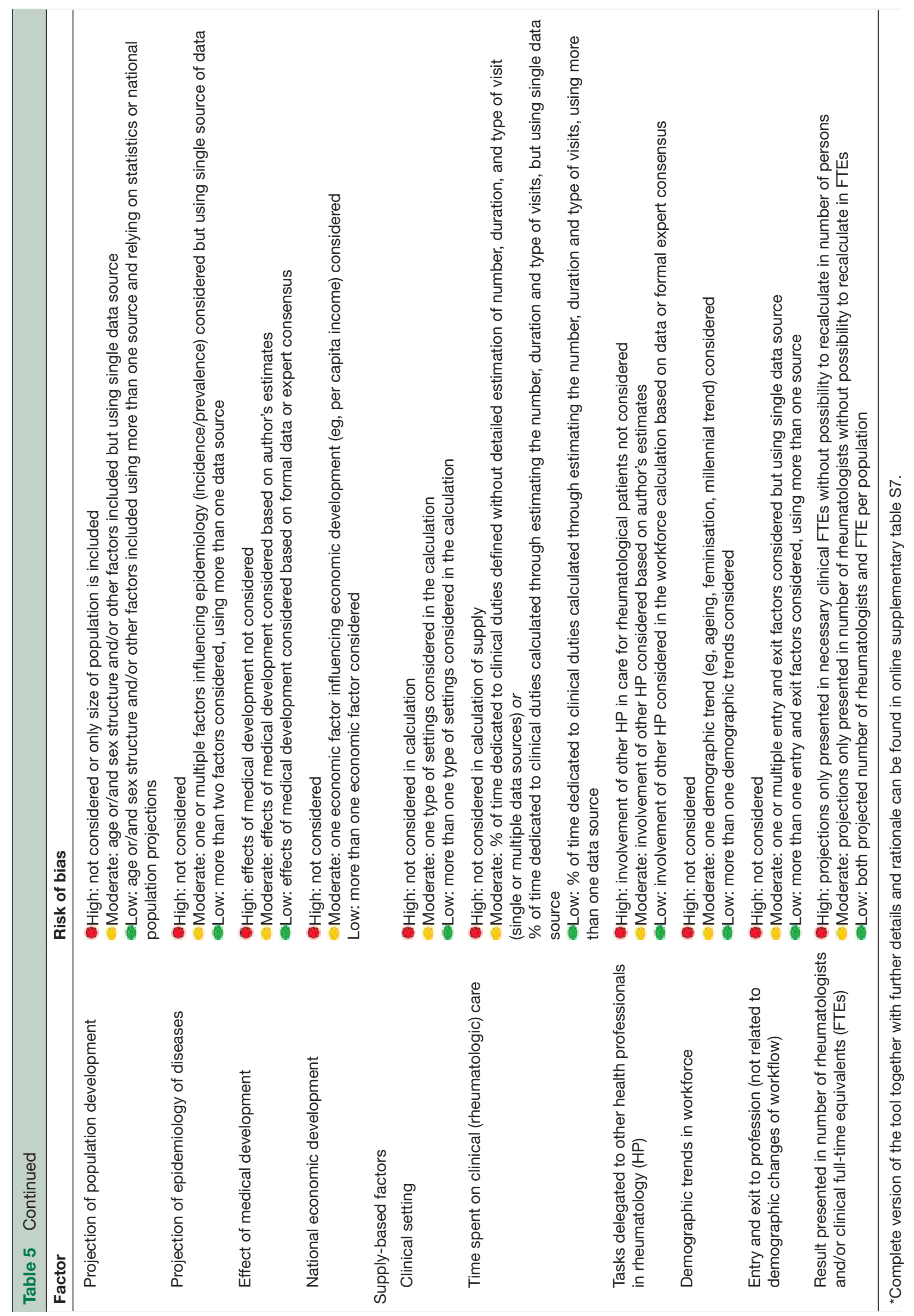



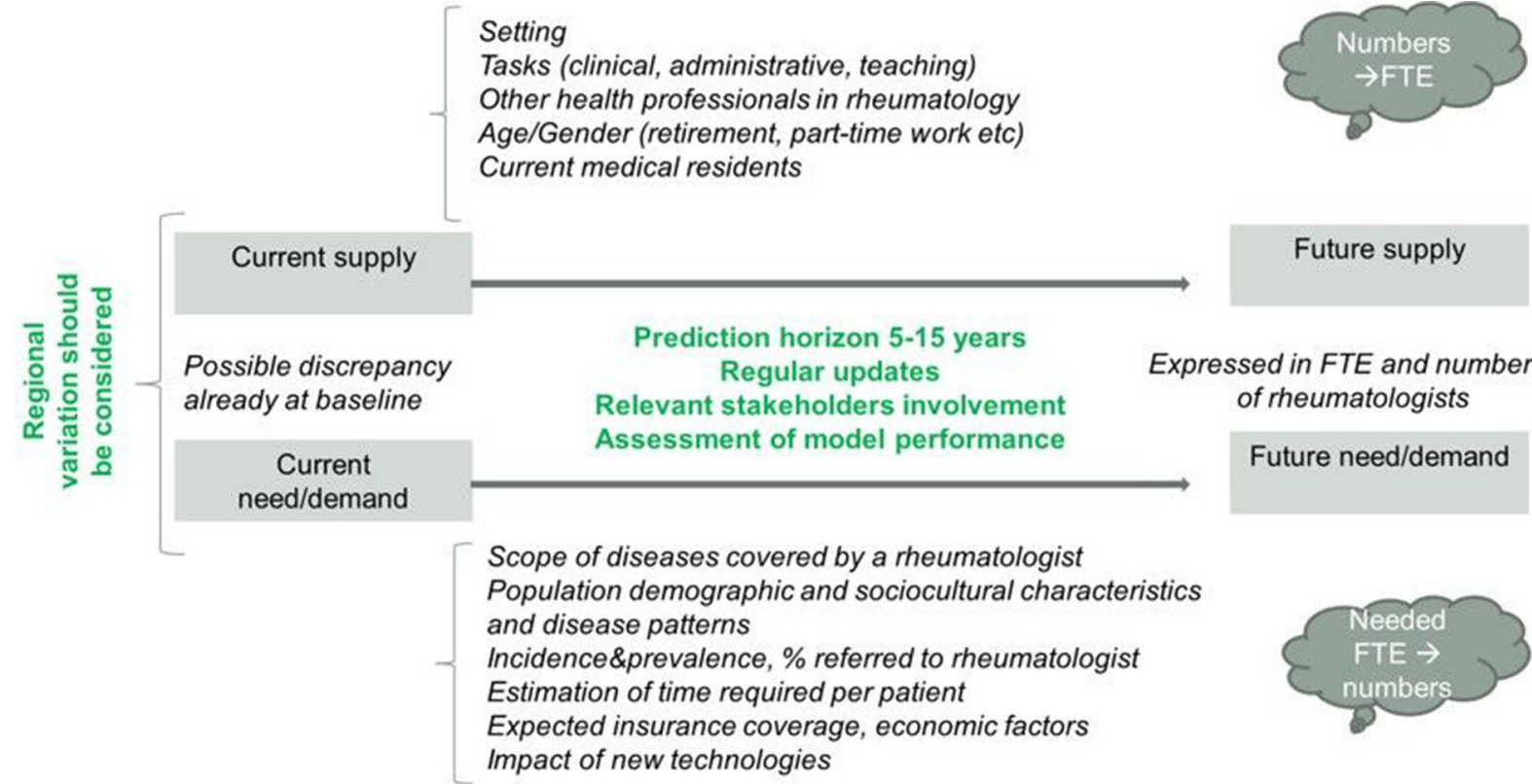

Figure 1 Structure of comprehensive workforce prediction studies. The figure illustrates the logic of workforce prediction planning and the factors that should be considered in a low risk of bias model. Planning should adopt an integrated model that includes a number demand/need and supply factors. Prediction should be optimally made for 5-15 years' horizon, with regular updates and performance assessment. Baseline imbalance between need/demand and supply should be taken into account. Uncertainty analyses should be done to test the critical assumptions. Relevant stakeholders should be consulted throughout the process. Results of the prediction should be convertible to headcounts and full-time equivalents (FTEs) to facilitate decision-making process at different levels.

other workforce prediction studies. The appraisal of existing models in rheumatology revealed that none of the studies had low risk of bias scores for all items; rather, the majority of studies had moderate to high bias in several categories. For several parameters, such as the effects of medical developments on future workforce need, none of the studies scored with a low risk of bias; nonetheless, we feel that meeting requirements for a low risk of bias for these factors is realistic and should be the target of future studies.

Our study has several limitations. First, the studies included in the two literature searches were limited to published literature and over several decades. Although we used a sensitive approach to identify workforce studies in rheumatology as well as SLRs in other medical fields, we cannot exclude that some relevant papers were missed. In countries with highly centralised healthcare planning, prediction models may not have been published and medical societies (which were contacted to retrieve unpublished literature) may not have been involved in these exercises and thus not aware of existing studies. Nonetheless, the grey literature search identified reports about supranational efforts (ie, EU and OECD) which summarised workforce prediction practices in healthcare planning in different countries. ${ }^{8} 12$ These reports from respected agencies, while having different focuses and thus not meeting the inclusion criteria of any of our searches, were reviewed, reassuring the task force that it is unlikely that any substantial parameters have been missed. However, most of the research has been done in the USA and Canada, which present only one part of the health systems of the Western world. Next, this review had a limited focus on prediction of the requirement of rheumatologists and left beyond the scope detailed review of workforce planning for other health professionals involved in care for patients with RMDs. Other limitations refer to the subjective character of the risk of bias tool and the absence of reliable methods for external validation of the quality of workforce studies. Future workforce prediction should thus pay more attention to the validation and assessment of the model performance in order to identify the key threats to model validity and the parameters with the highest priority. It should be recognised that certain factors affecting workforce requirement cannot be foreseen at time of model conduction (eg, social media were unknown in the last millennium but may affect demand today and in future), hence a regular update of the model is essential in order to increase the validity of predictions.

While workforce planning is not an exact science, it has an important role in the dialogue between different stakeholders to guide the decisions around workforce training and more general organisation of healthcare in order to cover the expected future demand of the population. $^{12}$ The current study provides an important and novel synthesis of contemporary workforce prediction practices. The existing evidence on workforce prediction in rheumatology and other fields is scarce, heterogeneous 
and of low to moderate quality. The workforce prediction risk of bias tool should facilitate future evaluation of workforce prediction studies.

\section{Author affiliations}

'Department of Health Studies, Institute of Occupational Therapy, FH JOANNEUM University of Applied Sciences, Bad Gleichenberg, Austria

${ }^{2}$ Department of Internal Medicine, Division of Rheumatology, Maastricht University Medical Center and CAPHRI Research Institute, Maastricht, The Netherlands ${ }^{3}$ Department of Rheumatology and Clinical Immunology, Charitè University Medicine, Berlin, Germany

${ }^{4}$ Division of Rheumatology, Medical University Vienna, Vienna, Austria

${ }^{5}$ Division of Rheumatology, ASL3-Azienda Sanitaria Genovese, Genova, Italy

${ }^{6}$ Department of Rheumatology \& Clinical Immunology, University Medical Center Utrecht, Utrecht, The Netherlands

${ }^{7}$ Division of Clinical Immunology \& Rheumatology, University of Zagreb School of Medicine, Zagreb, Croatia

${ }^{8}$ Department of Rheumatology, Centro Hospitalar Médio Tejo, Torres Novas, Portugal ${ }^{9}$ Columbia University Medical Center, New York City, New York, USA

${ }^{10}$ Division of Rheumatology, University Hospital of Geneva, Geneva, Switzerland

${ }^{11}$ Rheumatology Department, Sorbonne Université, Paris, and Pitié Salpêtrière Hhospital APHP, Paris, France

${ }^{12}$ Department of Rheumatology, Diakonhjemmet Hospital, Oslo, Norway

${ }^{13}$ Division of Rheumatology and Department of Health Sciences Research, Mayo

Clinic College of Medicine, Rochester, Minnesota, USA

${ }^{14}$ Department of Rheumatology, Hospital General Universitario de Elda, Elda, Spain

${ }^{15}$ Section for Outcomes Research, Medical Unversity Viennna, Center for Medical

Statistics, Informatics, and Intelligent Systems, Vienna, Austria

${ }^{16}$ Faculty of Medicine, Department of Internal Medicine, Division of Rheumatology,

University of Debrecen, Debrecen, Hungary

${ }^{17}$ EULAR Standing Committee of PARE, Zurich, Switzerland

${ }^{18}$ Deutsches Rheuma-Forschungszentrum, Berlin, Germany

${ }^{19}$ Department of Rheumatology, Hospital of Bruneck, Bruneck, Italy

${ }^{20}$ Department of Rheumatology and Immunology, Medical University Graz, Graz,

Styria, Austria

${ }^{21}$ Department of Rheumatology, Leiden University Medical Centre, Leiden, and

Zuyderland Medical Center, Heerlen, The Netherlands

Acknowledgements We thank the societies of rheumatology that answered our request for rheumatology workforce calculations at the national level, as well as authors of previous studies who provided information about post-evaluations of the model. Furthermore, we want to thank the EULAR Executive Assistant, Ms Patrizia Jud, who supported our inquiries to the national societies of rheumatology.

Contributors All coauthors contributed to the development of the study design and outline. LF has developed and run the library searches. JU, PP, FB, CD and SR have analysed and synthesised the data. JU and PP have drafted the first version of the manuscript, and all authors have critically reviewed and agreed with the final version of the manuscript.

Funding This study is part of the EULAR 'points to consider' for the conduction of workforce requirement studies in rheumatology funded by the European League Against Rheumatism (EULAR), grant number EPI016.

Competing interests None declared.

Patient consent Not required.

Provenance and peer review Not commissioned; externally peer reviewed. Data sharing statement № additional data are available.

Open access This is an open access article distributed in accordance with the Creative Commons Attribution Non Commercial (CC BY-NC 4.0) license, which permits others to distribute, remix, adapt, build upon this work non-commercially, and license their derivative works on different terms, provided the original work is properly cited, appropriate credit is given, any changes made indicated, and the use is non-commercial. See: http://creativecommons.org/licenses/by-nc/4.0

\section{REFERENCES}

1. Vos T, Flaxman AD, Naghavi M, et al. Years lived with disability (YLDs) for 1160 sequelae of 289 diseases and injuries 1990-2010: a systematic analysis for the Global Burden of Disease Study 2010. Lancet 2012;380:2163-96.
2. Briggs AM, Cross MJ, Hoy DG, et al. Musculoskeletal health conditions represent a global threat to healthy aging: a report for the 2015 World Health Organization World Report on Ageing and Health. Gerontologist 2016;56:S243-55.

3. Smolen JS, Landewé R, Bijlsma J, et al. EULAR recommendations for the management of rheumatoid arthritis with synthetic and biological disease-modifying antirheumatic drugs: 2016 update. Ann Rheum Dis 2017;76:960-77.

4. van der Heijde D, Ramiro S, Landewé R, et al. 2016 update of the ASAS-EULAR management recommendations for axial spondyloarthritis. Ann Rheum Dis 2017;76:978-91.

5. Gossec L, Smolen JS, Ramiro S, et al. European League Against Rheumatism (EULAR) recommendations for the management of psoriatic arthritis with pharmacological therapies: 2015 update. Ann Rheum Dis 2016;75:499-510.

6. Lard LR, Huizinga TW, Hazes JM, et al. Delayed referral of female patients with rheumatoid arthritis. J Rheumatol 2001;28:2190-2.

7. Zink A, Braun J, Gromnica-Ihle E, et al. Memorandum der deutschen gesellschaft für rheumatologie zur versorgungsqualität in der rheumatologie-update 2016. Zeitschrift für Rheumatologie 2017;76:195-207.

8. Ono T, Lafortune G, Schoenstein M. Health workforce planning in OECD countries: a review of 26 projection models from 18 countries. Paris, 2013.

9. Dejaco C, Lackner A, Buttgereit F, et al. Rheumatology workforce planning in western countries: a systematic literature review. Arthritis Care Res 2016;68:1874-82.

10. Domagała A, Klich J. Planning of Polish physician workforcesystemic inconsistencies, challenges and possible ways forward. Health Policy 2018;122:102-8.

11. Kroezen M, Van Hoegaerden M, Batenburg R. The joint action on health workforce planning and forecasting: results of a European programme to improve health workforce policies. Health Policy 2018:122:87-93.

12. Malgieri A, Michelutti P, Van HM. Handbook on health workforce planning methodologies across EU countries. Bratislava, 2015.

13. Dejaco C, Putrik P, Unger J. EULAR 'points to consider' for the conduction of workforce requirement studies in rheumatology. RMDopen 2018.

14. Marder WD, Meenan RF, Felson DT. The present and future adequacy of rheumatology manpower. Arthritis Rheum 1991;34:1209-17.

15. Deal CL, Hooker R, Harrington T, et al. The United States rheumatology workforce: supply and demand, 2005-2025. Arthritis Rheum 2007;56:722-9.

16. US Department of Health and Human Services, Health Resources and Services Administration, National Center for Health Workforce Analysis. Technical documentation for health resources and services administration's health workforce simulation model. Maryland: Rockville, 2015.

17. Battafarano DF, Ditmyer M, Bolster MB, et al. 2015 American College of Rheumatology Workforce Study: Supply and Demand Projections of Adult Rheumatology Workforce, 2015-2030. Arthritis Care Res 2018;70:617-26.

18. Zummer M, Henderson J. Whither rheumatology or wither rheumatology? Can Med Assoc J 2000;10:5-7.

19. Edworthy S. Canadian rheumatologists: an endangered species. Can Med Assoc J 2000;10:6-10.

20. Hanly JG. Manpower in Canadian academic rheumatology units: current status and future trends. J Rheumatol 2001;28:1944-51.

21. German Society for Rheumatology C for C. Anhaltszahlen zum Bedarf an internistischen Rheumatologen, Kinderrheumatologen, Akutkrankenhausbetten und medizinischer Rehabilitation, 2008: 58-62.

22. Raspe H. [Basic principles of community, continuous and cooperative management of patients with chronic rheumatic diseases in Germany]. Z Rheumatol 1995;54:192-7.

23. services Drheumatology. District rheumatology services. A report by the Committee on Rheumatology of the Royal College of Physicians of London. Br J Rheumatol 1988;27:54-61.

24. Rowe I, Neil S, Ruth R. Rheumatology. UK Consult physicians Work with patients2013:235-50.

25. Lázaro y De Mercado P, Blasco Bravo AJ, Lázaro y De Mercado I, et al. Rheumatology in the community of Madrid: current availability of rheumatologists and future needs using a predictive model. Reumatol Clin 2013;9:353-8.

26. Ogryzlo MA. Editorial: Specialty of rheumatology-manpower requirements. J Rheumatol 1975;2:1-4.

27. O'Brien-Pallas L, Baumann A, Donner G, et al. Forecasting models for human resources in health care. J Adv Nurs 2001;33:120-9. 
28. Reid B, Kane K, Curran C. District nursing workforce planning: a review of the methods. Br J Community Nurs 2008;13:525-30.

29. Hawthorne N, Anderson C. The global pharmacy workforce: a systematic review of the literature. Hum Resour Health 2009;7:48.

30. Mayer ML, Skinner AC, many T. Too many, too few, too concentrated? A review of the pediatric subspecialty workforce literature. Arch Pediatr Adolesc Med 2004;158:1158-65.

31. Beck AJ, Boulton ML. Building an effective workforce: a systematic review of public health workforce literature. Am J Prev Med 2012;42-S6-16.

32. Feil EC, Welch HG, Fisher ES. Why estimates of physician supply and requirements disagree. JAMA 1993;269:2659-63.

33. Curson JA, Dell ME, Wilson RA, et al. Who does workforce planning well? Workforce review team rapid review summary. Int $J$ Health Care Qual Assur 2010;23:110-9.
34. Rafiei S, Mohebbifar R, Hashemi F, et al. Approaches in health human resource forecasting: a roadmap for improvement. Electron Physician 2016;8:2911-7.

35. Tomblin Murphy G, Birch S, MacKenzie A, et al. Simulating future supply of and requirements for human resources for health in highincome OECD countries. Hum Resour Health 2016;14:77.

36. Hempel S, Maggard G, Ulloa J. Rural healthcare workforce: a systematic review. 226. Washington, 2015.

37. Lang G, Reischl B, Hauser C. Impact of changing social structures on stress and quality of life: individual and social perspectives. Vienna: Review and Inventory of National Systems and Policy, 2003.

38. American College of Rheumatology, 2016. The 2015 workforce study of rheumatology specialists in the United States: survey results. Available from:https://www.rheumatology.org/portals/0/files/ACRWorkforce-Study-2015.pdf [Accessed26 May 2017]. 